\section{IS A SHORT COURSE OF AZITHROMYCIN EFFECTIVE IN THE TREATMENT OF MILD TO MODERATE PELVIC INFLAMMATORY DISEASE (PID)?}

${ }^{1}$ Gillian Dean* ${ }^{1}$ Jennifer Whetham, ${ }^{1}$ Suneeta Soni, ${ }^{1}$ Louise Kerr, ${ }^{2}$ Linda Greene, ${ }^{3}$ Jonathan Ross, ${ }^{4}$ Caroline Sabin. ${ }^{1}$ Brighton \& Sussex University Hospitals NHS Trust, Brighton, UK; ${ }^{2}$ St Mary's Hospital, Paddington, London, UK; ${ }^{3}$ University Hospitals Birmingham NHS Foundation Trust, Birmingham, UK; ${ }^{4}$ Research Department of Infection and Population Health, UCL, London, UK

\subsection{6/sextrans-2016-052718.6}

Background/introduction Crucial to treatment success in PID is adherence to therapy. All guidelines recommend 14-days of therapy although many women fail to complete 2-weeks, particularly if they experience side-effects. A shorter course of antibiotics may offer a valuable treatment alternative.

Aim(s)/objectives To compare clinical efficacy/acceptability of standard PID treatment 14-days with 5-day course of antibiotics for mild-moderate PID (pain for $<30$ days).

Methods A multicentre, open-label, non-inferiority RCT comparing arm-1 (ofloxacin/metronidazole) with arm-2 (azithromycin $1 \mathrm{~g}$ day-1; 500mg od day-2-5, metronidazole/ceftriaxone). Efficacy was measured using standard pain-scores at baseline and 14-21 day follow-up looking for a 70\% reduction; women who failed to complete treatment/return for follow-up were considered treatment failures.

Results $\mathrm{N}=313$ (152 arm-1, 162 arm-2 with similar baseline characteristics). Median age 25. Lower abdo-pain 95\%, discharge 64\%, dyspareunia 53\%. Baseline pain-score median 8/36 (range 1-26); day 14-21 0/36 (range 0-18). Considering women who failed to complete therapy/return for follow-up as failures, the proportion with $70 \%$ pain reduction was $46.7 \%$ for arm-1; $42.2 \%$ for arm-2 ( $\mathrm{p}=0.49$, difference in proportions (arm-2 minus arm-1) $-4.5 \%$ (95\% CI $-15.5 \%, 6.5 \%)$ ). For those women completing therapy the proportion with a $70 \%$ pain reduction was $68.9 \%$ for $\operatorname{arm}-1 ; 57.6 \%$ for arm-2 $(\mathrm{p}=0.11$, difference in proportions $-11.3 \%$ (95\% CI $-23.9 \%,-1.3 \%)$. There were no significant differences in reported side effects except diarrhoea: $33.6 \%$ arm-1 vs $78.1 \%$ arm-2 ( $=0.0001)$.

Discussion/conclusion In terms of pain reduction we could not demonstrate that the shorter azithromycin course was non-inferior to the standard-of-care. Patients also experienced significantly more diarrhoea. This study highlights the importance of using evidence-based treatment regimens.

\section{DIGITAL HEALTH AND REMOTE DIGITAL CONSULTATIONS: VIEWS AND EXPERIENCES IN SEXUAL HEALTH CLINIC ATTENDEES}

Jake Bayley*, Marie McNulty, Michael O'Hanlon, Jennifer Hong. Barts Health NHS Trust, London, UK

10.1136/sextrans-2016-052718.7

Background/introduction Digital health is becoming increasingly important in the NHS. Use of apps and remote digital consultations (RDC) may improve patient access and satisfaction, but more data on attitudes in sexual health clinic attendees are needed.

$\operatorname{Aim}(\mathrm{s}) /$ objectives Assess the views of using digital health in sexual health clinic attendees.

Methods Patient-directed questionnaires were completed by patients attending a sexual health service. Demographic data were collected, along with acceptability and use of apps, websites and RDC.

Results 231 surveys were returned. 85\% (175/206) of participants would be happy to use a website for sexual health; $39 \%$ (82/208) find using an app acceptable. Education to A-level or above significantly improved acceptability of using digital health for RDC (see Table 1). A previous STI versus no STI in the last 12 months significantly improved acceptability of using an app for sexual health $(22 / 40$ versus $58 / 165, \mathrm{p}=0.02)$ and consenting for a recording of their RDC in clinic notes (17/38 versus 44/164, $\mathrm{p}=0.02$ ).

\begin{tabular}{|c|c|c|c|c|}
\hline & Overall & $\begin{array}{l}\text { Educated to } \\
\text { GCSE level } \\
\text { or less }\end{array}$ & $\begin{array}{l}\text { Educated to } \\
\text { A-level or higher }\end{array}$ & p-value \\
\hline $\begin{array}{l}\text { Currently have a device } \\
\text { for video consultation } \\
\text { (i.e. Skype or FaceTime) }\end{array}$ & $84 \%(173 / 207)$ & $67 \%(31 / 46)$ & $90 \%(137 / 152)$ & 0.001 \\
\hline $\begin{array}{l}\text { Give consent for face } \\
\text { to face remote } \\
\text { digital consultation }\end{array}$ & $51 \%(105 / 207)$ & $37 \%(17 / 46)$ & $56 \%(85 / 152)$ & 0.01 \\
\hline $\begin{array}{l}\text { Find web cam use } \\
\text { acceptable for remote } \\
\text { appointments }\end{array}$ & $40 \%(81 / 202)$ & $26 \%(12 / 46)$ & $46 \%(68 / 147)$ & 0.02 \\
\hline
\end{tabular}

Discussion/conclusion Most participants find using a website acceptable, however the use of apps less so. RDC are acceptable for only one in two of all sexual health attendees, and less so for patients with lower educational attainment. Only four in ten would allow a recording of a digital consultation, with confidentiality stated as the main concern. Fewer responses were received from patients with a lower educational attainment, which may affect generalisability of these data. We should be mindful that a mixture of digital and traditional health is needed to accommodate all service users.

\section{O008 TRIAGE REVIEW: SHOULD THEY STAY, OR SHOULD THEY GO?}

Susanna Currie*, Elizabeth Nicol, Gabriel Schembri. Manchester Centre for Sexual Health, Manchester, UK

\subsection{6/sextrans-2016-052718.8}

Background BASHH guidance for GUM services advises access within 48 hours for all and on the day review for emergencies. GU services have varying policies for when capacity is reached, ranging from 'closed door' policies to triaging all, however, there are concerns that patients with significant infections may be turned away. Since 2010 our inner city clinic has used triage forms.

Aims To investigate the burden of STIs in individuals who were turned away after triage, and assess the efficacy of our triage system

Methods Review of all triaged patients between 5/1/15-24/3/15. Results 698 patients triaged: 359M; 336F; 3 unknown. Median age 23 years (range 16-86). 488 (70\%) were turned away: 255M; 230F; 3 unknown; median age 23 years (range 16-73). Warts/lumps/bumps (15\%), urinary symptoms (15\%) and 
abnormal discharge $(15 \%)$ were the most common presenting symptoms and most likely to be turned away.

\begin{tabular}{lll} 
Abstract $\mathbf{0 0 0 8}$ Table $\mathbf{1}$ & Triage review & \\
\hline $\begin{array}{l}\text { Diagnosis of all accepted and turned away } \\
\text { re-attenders }\end{array}$ & $\begin{array}{l}\text { Number } \\
\text { diagnosed }\end{array}$ & $\begin{array}{l}\text { Number initially } \\
\text { turned away }\end{array}$ \\
\hline Chlamydia & 33 & $16(49 \%)$ \\
Gonorrhoea & 19 & $8(42 \%)$ \\
Primary Syphilis & 2 & $1(50 \%)$ \\
PID/epididymitis & 26 & $9(35 \%)$ \\
Non-specific genital infection & 34 & $17(50 \%)$ \\
\hline
\end{tabular}

$224(46 \%)$ of those turned away, never returned.

Conclusions Turned away patients who re-attended had a significant number of STIs and BASHH concerns are justified. Patients who never return heighten these concerns. Management of excess demand in the current financial climate is challenging, but closer links between clinics in a region, central booking systems and social media could help to direct individuals to clinics with availability.

\section{EVALUATION OF A PILOT OF INTERNET REQUESTED CHLAMYDIA TEST KITS IN 25 TO 34 YEAR OLDS}

${ }^{1}$ Deborah Shaw*, 'John Saunders, ${ }^{2}$ Joanne Keal, 'Sarah Woodhall. 'Public Health England, London, UK; ${ }^{2}$ Lincolnshire County Council, Lincoln, UK

\section{$10.1136 /$ sextrans-2016-052718.9}

Background In the UK, Chlamydia is most prevalent in those aged 16-24 years. However, $1.5 \%$ of women and $1.0 \%$ of men aged 25-34 years are estimated to be infected. Attending healthcare venues may be challenging in rural settings and internetrequested tests may help individuals to access testing. We report results from a pilot of internet-requested testing among 25 to 34 year-olds resident in a rural region of England.

Aim(s) To evaluate the pilot of internet-requested chlamydia test kits in 25 to 34 year-olds.

Methods Internet-requested test kits were made available to those aged 25 to 34 years through a dedicated website from $1^{\text {st }}$
April to $31^{\text {st }}$ December 2015. Number of test kit requests, returns, positivity (positive tests/number tested) and cost data were reviewed for those aged 15 to 24 and 25 to 34 years.

Results The proportion of kits that were returned was significantly higher among the older age group (Table 1). Positivity was similar in the two age groups. The average cost per test and per positive was $£ 22.58$ and $£ 244.47$, respectively, in the younger group and $£ 22.08$ and $£ 303.45$ for the older group.

Discussion The pilot shows that chlamydia internet tests were accessed by an older group who were at significant risk of infection as evidenced by the positivity in that group. Return rates were high. Provision of internet tests to older age groups may represent an attractive option for some local commissioners and providers.

\section{USE AND PERCEPTIONS OF THE ONLINE CHLAMYDIA PATHWAY (OCP): FINDINGS FROM QUALITATIVE INTERVIEWS AMONG PEOPLE TREATED FOR CHLAMYDIA}

${ }^{1}$ Catherine Aicken*, ${ }^{2}$ Lorna J Sutcliffe, ${ }^{1,2}$ Jo Gibbs, ${ }^{2}$ Laura Tickle, ${ }^{3}$ S Tariq Sadiq, ${ }^{1}$ Catherine H Mercer, ${ }^{1}$ Pam Sonnenberg, ${ }^{2}$ Claudia S Estcourt, ${ }^{1}$ Maryam Shahmanesh. ' University College London, London, UK; ${ }^{2}$ Queen Mary University of London, London, UK; ${ }^{3}$ St. George's University of London, London, UK

\subsection{6/sextrans-2016-052718.10}

Introduction Within the $\mathrm{STI}^{2}$ consortium, we conducted exploratory studies of an innovative Online Chlamydia Pathway (OCP: results service, automated clinical consultation, electronic prescription via community pharmacy, online partner management, with telephone helpline support). Access to traditional services was facilitated where appropriate.

Objectives To describe patients' use and perceptions of the OCP. Methods In-depth qualitative interviews with 40 purposivelysampled OCP users (21/40 female, aged 18-35) analysed thematically.

Results Interviewees chose the OCP to obtain treatment rapidly, conveniently and inconspicuously, within busy lifestyles that impeded clinic access. They described completing the online consultation promptly and discreetly, often using smartphones. Many found the online information provided comprehensive, but those who completed the consultation in public locations

Abstract 0009 Table 1 Test requests, returns, tests and positivity by age group

\begin{tabular}{|c|c|c|c|c|c|c|}
\hline & \multicolumn{2}{|c|}{15 to 24 years } & \multicolumn{2}{|c|}{25 to 34 years } & \multirow[t]{2}{*}{ Unadjusted OR $(95 \% \mathrm{Cl})$} & \multirow[t]{2}{*}{$p$ value } \\
\hline & $\mathrm{N}$ & $\%$ & n & $\%$ & & \\
\hline Kits requested & 2,203 & & 571 & & & \\
\hline $\begin{array}{l}\text { Total test kits } \\
\text { returned }\end{array}$ & 1,548 & $70.3 \%$ & 426 & $75 \%$ & 1.24 (1.01 to 1.53$)$ & 0.042 \\
\hline \multicolumn{7}{|l|}{$\begin{array}{l}\text { Suitable specimen } \\
\text { returned for testing }\end{array}$} \\
\hline Total specimens & 1,508 & & 411 & & & \\
\hline Specimens from women & 1,062 & & 252 & & & \\
\hline Specimens from men & 446 & & 159 & & & \\
\hline \multicolumn{7}{|c|}{ Test positive for chlamydia } \\
\hline Total & $139 / 1508$ & $9.2 \%$ & $31 / 411$ & $7.5 \%$ & $0.80(0.54$ to 1.21$)$ & 0.29 \\
\hline Women & $84 / 1062$ & $7.9 \%$ & $14 / 252$ & $5.6 \%$ & 0.68 (0.38 to 1.23$)$ & 0.20 \\
\hline Men & $55 / 446$ & $12.3 \%$ & $17 / 159$ & $10.7 \%$ & 0.85 (0.49 to 1.52$)$ & 0.58 \\
\hline
\end{tabular}

